\title{
LA ANTROPOLOGíA SOCIAL EN LA ARGENIINA: UN PRODUCTO DE LA DEMOCRACIA
}

\author{
Hugo E. Ratier \\ Universidad de Buenos Aires - Argentina \\ Roberto R. Ringuelet \\ Universidad Nacional de La Plata - Argentina
}

Resumo: A antropologia na Argentina teve inicio com a antropologia física, arqueologia e folclore. Recentemente, na década de 60, surgiram orientações que propuseram a prática uma antropologia social. Tal disciplina é conceitualizada como ampla quanto ao seu objeto (o qual inclui não apenas índios e camponeses), comprometida com problemas urgentes do país e capaz de trazer soluções. Essa concepção foi combatida por correntes teóricas hegemónicas em épocas ditatoriais que proibiram sua prática, perseguiram professores e fecharam cursos. Somente com a restauração da democracia em 1983 a disciplina consegue consolidar-se.

Abstract: In the beginning, Argentinian anthropology was confined to physical anthropology, arqueology and folklore. During the sixties, a new approach, from the field of social anthropology, appeared. The discipline had broad aims as to its object (including more than Indians and peasants), and its compromise with finding solutions for the country's urgent problems. This conception was threatened by hegemonic theoretical trends during the years of dictatorship which prohibited its practice, persecuted teachers and closed courses. The real consolidation of the discipline only became possible in 1983 with the restoration of democracy.

\section{Comienzos de la antropología en la Argentina}

El modelo agroexportador se instaló en la Argentina a partir de su “modernización” iniciada con la caída de Juan Manuel de Rosas (1852) e intensificada por la acción de la llamada generación del 80. La plena integración del país al sistema mundial se correspondió con el fomento de la investigación científica en moldes positivistas. 
En los comienzos el interés científico se vinculó a las Ciencias Naturales, pudiendo establecerse una secuencia de estudios que parten de la geología, siguen con la paleontología y culminan en la arqueología. La temática del origen del hombre, que alimentaba la polémica creacionismo-evolucionismo en Europa, llega al Plata. Florentino Ameghino, notable autodidacta, marcó rumbos insuperados en la paleontología pampeana, interpreta la geología de la región y arriesga la audaz hipótesis de un origen americano para la especie humana. Diez años apenas habían transcurrido desde la instauración de la ciencia prehistórica por Boucher de Perthes cuando comienza su labor sistemática y otros diez años más tarde publica su obra fundamental La Antigüedad del Hombre en el Plata. En 1910 el norteamericano Hrdlicka desautorizó su posición ante la comunidad científica.

Desde el principio el interés antropológico se vinculó a los indios muertos (los únicos buenos, según el credo racista). A la discusión sobre el origen del hombre sucederán otras sobre la interpretación de los restos arqueológicos del noroeste. De los indios vivos se ocuparían pioneros como Estanislao Zeballos y Francisco P. Moreno, quienes realizaron expediciones a la Patagonia; el primero poco antes de la derrota indígena a manos del ejército, el otro inmediatamente después, acompañando a las tropas. En base a las colecciones antropológicas y paleontológicas de Moreno, se creó un Museo Antropológico y arqueológico en 1877 que, luego de fundada la ciudad de La Plata, obtuvo su localización definitiva en la nueva capital de la Provincia de Buenos Aires en el año 1887, con su nombre actual: Museo de La Plata. En 1905, el Museo se transfirió a la Universidad Nacional de La Plata con la organización de una Escuela de Ciencias Naturales y desde 1949, esta última pasó a ser la actual Facultad de Ciencias Naturales y Museo. Las actuales universidades de La Plata y Buenos Aires forman parte del conjunto de las universidades más grandes del país. En cuanto al Museo de La Plata, se integra al conjunto de los grandes museos nacionales.

En términos generales nuestros primeros antropólogos fueron polivalentes, practicando tanto la antropología física como la arqueología y la etnografía indígena. Todo como parte de una indagación sobre el pasado, ya que la eliminación del indio se juzgaba inevitable y deseable. Interesaban los bienes culturales que dieran testimonio de antiguas costumbres, como un apoyo a la indagación arqueológica. Lo etnográfico se daba en el marco de un naturalismo global, que aspiraba a relevar científicamente geología, flora, fauna y antropología de las múltiples áreas desconocidas del país. El 
porvenir de las naciones indígenas no preocupaba, en tanto se suponía que, de no ser eliminadas, terminarían por asimilarse a la cultura dominante. Demográficamente, el crecimiento del país se confiaba a la importación de inmigrantes. Indios y criollos deberían cederles sitio.

A veces por ese mismo afán de rescate, otras como parte de un movimiento nacionalista que reaccionaba a la invasión "gringa” y a la alteración de costumbres que suponía, se fomentó tempranamente la indagación folklórica, a efectos de rescatar costumbres y acervos culturales tradicionales. A esa tarea se entregaron antropólogos profesionales y aficionados locales. La folklorística, fué tal vez la única especialidad que no excluyó de su programa la puesta en práctica -resignificadas- de algunas de las costumbres que estudiaba y cuya vigencia, en parte, reivindicaba. De tal forma, brindó materia prima para los movimientos tradicionalistas.

\section{Antropólogos extranjeros y sus escuelas}

En el inicio se importaron científicos europeos para sentar las bases de nuestra ciencia. Nos referiremos a algunos de ellos por su influencia en el desarrollo de la especialidad que queremos reseñar.

El antropólogo italiano José Imbelloni registró dos estadías en la Argentina. Una, antes de la Primera Guerra Mundial, a la que pertenecen dos trabajos de juventud de corte positivista referidos a la guerra (Garbulsky, 1987). Contrario al pacifismo va a la península a combatir. Regresa en 1921 y, ya en la década del 30, será el introductor en nuestro país de la escuela histórico-cultural de raigambre austro-alemana. Tal escuela tendrá larga influencia sobre la antropología argentina subsiguiente, pero también sobre otras de Latinoamérica. Recordemos la introducción a O Negro Brasileiro de Arthur Ramos, por ejemplo.

Pese a sus antecedentes positivistas (Garbulsky, 1987) Imbelloni se filió al difusionismo y mantuvo posturas racistas. El antropólogo italiano propició la radicación en el país de científicos provenientes de los países del Eje, como Osvaldo Menghin, Branimiro Males y, entre los juniors, Marcelo Bórmida, joven oficial del ejército del Duce.

Otra vertiente teórica se instaló en Tucumán con Alfred Metraux, en la década del 30. Con él trabajó Enrique Palavecino, uno de los pocos etnógrafos de campo que se ocupó de indígenas. Pero avatares políticos minimizaron la influencia del antropólogo francés. 
Queremos remarcar que ese predominio de una escuela perimida en Europa y jamás difundida en Estados Unidos, tendría marcada importancia en la constitución de la antropología profesional en la Argentina y, en particular, en la situación de la Antropología Social. Cabe destacar que ese predominio sobrevivió a cambios de gobierno y prosperó en especial en los períodos autoritarios que usurparon el poder democrático en el país.

\section{La Antropología profesional: surgen las carreras}

El derrocamiento del gobierno peronista y la proscripción del político por él creado, instauraría un impasse peculiar en nuestra vida institucional. El regimen depuesto sería calificado como dictatorial y quienes lo sustituyen se autocalificarán como democráticos, excluyendo al peronismo de la participación política nacional.

En la universidad se reinstalan las instituciones formales de cogobierno de la tradición reformista. ${ }^{1}$ Se expulsa a los profesores peronistas y se lanza un movimiento modernizante. Como parte de éste y a tono con la ola desarrollista que recorrió el continente, se implantaron nuevos cursos de Ciencias Sociales. Se aspiraba a formar profesionales que analizaran la confusa realidad sociopolítica y sus múltiples enigmas. Entre ellos, la persistencia del peronismo como movimiento mayoritario pese a su puesta fuera de la ley.

Acaba así la época de la ensayística filosófico-social y se inaugura la de los estudios sistemáticos, científicos, apoyados en un aparato metodológico forjado en los países anglosajones. En la Universidad de Buenos Aires se crearon hacia 1956-58 las nuevas Licenciaturas en Sociología, Psicología. Ciencias de la Educación y Ciencias Antropológicas.

En La Plata, con la inauguración de la Facultad se crean las licenciaturas en Paleontología, Botánica. Zoología y Geología, que venían En La Plata, con la creación de la Facultad en 1949 se formalizaron las actualizándose en métodos y teorías. La Antropología, sin embargo, tendrá que esperar una década para transformarse en carrera independiente, en 1958 y, en la década siguiente, aparece Antropología Social como materia optativa, junto al conjunto

1 La Reforma Universitaria es un movimiento democratizador de la vida académica impulsado por los estudiantes cordobeses, de gran influencia en América Latina. Entre otras cosas, propicia el cogobierno de las casas de estudio por estudiantes, docentes y graduados y la relación activa entre universidad y comunidad. 
de materias obligatorias de tipo etnológico - etnográfico, antropobiológico y arqueológico. Observemos que lo biológico, desde las disciplinas de Ciencias Naturales de la Facultad, no se impuso a la Antropología como necesidad teórica. Dentro mismo de la carrera, la llamada Antropología Biológica, ya no podía sostener las viejas teorías decimonónicas de cara al avance teórico de las Ciencias Naturales y creaba con dificultad un conocimiento propio moderno. La Etnología - Etnografía seguía en La Plata una línea culturalista alemana acorde con Buenos Aires, pero configurando una situación peculiar: Su imagen en la Facultad era anticientífica y de exotismo; su influencia se restringía a una subárea dentro de la carrera y era observada con recelo por los colegas naturalistas.

En La Plata, un aspecto global de la enseñanza fué -más allá del sentido holístico de la Antropología-, una visión totalizadora de las Ciencias, amasada en las diversas cursadas en la misma Facultad y en otras de Ciencias biológicas y Humanidades. En el período, la Arqueología es claramente hegemónica; ya en las décadas precedentes se venían organizando las grandes colecciones arqueológicas al compás del crecimiento museístico. Veamos que la Arqueología de aquellos años no desdeñaba el marco histórico - cultural pero, más bien, se empeñaba en una legalidad pragmática avalada por los vecinos naturalistas. El Dr. Eduardo M. Cigliano fué el arquetipo del enfoque mencionado y líder de un sector académico. La Facultad contó entonces con otro miembro fundamental por su influencia teórica y organizativa: El Dr. Alberto Rex Gonzalez, que adjuntó la impronta teórica del materialismo cultural de los EE. UU.

La importancia del Dr. Gonzalez para el desarrollo de una Antropología Social en La Plata tiene que ver, al menos, con tres aspectos: Primero, su gestión para traer al joven historiador orientado hacia la Antropología José Cruz, que cubriría por primera vez y por poco tiempo el curso optativo de Antropología Social, a mediados de los años 60; segundo, el hecho de constituirse en referente privilegiado para el conocimiento de las corrientes teóricas modernas de la Antropología; por último, la ayuda brindada a los recién graduados orientados hacia la Antropología Social para su inserción profesional.

En el caso de la carrera porteña de Antropología la orientación del curso no respondió al modelo desarrollista. Por el contrario, tanto la variante histórico-cultural como su posterior desarrollo fenomenológico proponen una historia reconstructiva como finalidad última dé las ciencias antropológicas. La arqueología pareció marcar el rumbo. A la datación estratigráfica establecida en la excavación, corresponde la diacronización de patrimonios relevados por 
el etnólogo o el folklorista. Se enfatizo la discusión evolucionismo-difusionismo y se soslayaron escuelas enteras de pensamiento, como el funcionalismo, el estructural-funcionalismo, el estructuralismo, todas las variantes del marxismo y cualquier escuela posterior. Diríamos que se eludieron los clásicos de la disciplina, como los pertenecientes a la escuela británica, el historicismo boasiano y la escuela sociológica francesa.

El estudiantado de Buenos Aires debió ir a buscar esos referentes en la carrera de Sociología, donde sí se frecuenta la bibliografía anglosajona, se enseña una metodología de investigación más consonante con el desarrollismo (el desarrollo de comunidad) y se dictaban seminarios sobre desenvolvimientos teóricos recientes, como el que Eliseo Verón ofreciera sobre el estructuralismo de Lévi-Strauss.

Como un negativo de la propuesta académica porteña, grupos de estudiantes fueron concibiendo como alternativa lo que comienzan a denominar antropología social. Se la piensa como una antropología volcada hacia problemas actuales del país y del continente, no limitada al relevamiento de culturas indígenas (etnología) y campesinas (folklore), basada en una concepción histórico-estructural distinta a la historiografía tentativa y con posibilidades de ser aplicada en la resolución de problemas concretos.

A esa antropología social sui generis se opuso firmemente el statuquo académico. En épocas dictatoriales prohibirían su ejercicio, acusándola de extremismo político. Explícitamente ofrecerían al gobierno de turno su concepción de la antropología como la más adecuada ideológicamente. Y colaborarían en la persecución a los profesionales enrolados en la nueva tendencia.

Teóricamente la así llamada antropología social abrevaba en fuentes convencionales: Redfield, Foster, Nadei y los que sostienen el modelo de desarrollo de comunidad, de singular fortuna. Es que los jóvenes antropólogos que consiguen empleos extra-académicos lo hacen en programas encuadrados en esa propuesta desarrollista. Se explora también la vertiente mexicana, con Ricardo Pozas Arciniegas, Aguirre Beltrán y otros indigenistas. Se lee Darcy Ribeiro. Se buscan también los neomarxismos europeos, así como los retoños del estructuralismo francés, y se abre la perspectiva hacia otras ciencias sociales, como la Sociología, la Historia Social y la Ciencia Política.

En La Plata, se configuraron expectativas teóricas semejantes a las de Buenos Aires, aunque en un escenario más facilitador; sea según hemos visto, 
por la presencia de aspectos favorables derivados de situaciones generales o acciones personales, sea por la constitución en el área que nos convoca de un relativo vacío de poder académico. El hecho es que, aunque fragmentariamente, los grupos de alumnos avanzados interesados en la Antropología Social, experimentando búsquedas semejantes a sus compañeros de Buenos Aires, tuvieron una guía inicial en el Profesor Cruz y en su propuesta de una Antropología Social de corle clásico. Cuando éste se va de la Universidad por el golpe militar del 66, los mismo alumnos gestionaron la incorporación del Profesor Mario Margulis, joven economista de Buenos Aires interesado ampliamente en las Ciencias Sociales, para que se hiciera cargo del curso que habandonara Cruz. Margulis acompañó la búsqueda teórica de los alumnos y la ordenó en el marco comprensivo del conjunto de las corrientes antropológicas - y ampliamente de las Ciencias Sociales - del momento. En el transcurso de los años hasta 1974, fué orientando su programa hacia las bases del materialismo dialéctico.

En este período se construye en La Plata y en Buenos Aires un sesgo de la Antropología Social argentina, cual es una cierta heterodoxia teórica disciplinaria merced a la fuerte integración inicial de la Antropología Social en el conjunto de las Ciencias Sociales. En La Plata también se cumplió un proceso de mestizaje intelectual, pletórico y desordenado que abrevaba en la Sociología, en la Economía Política y en la Comunicación Social, junto a prácticas políticas que se encontraban en el antiimperialismo.

La llegada de graduados del exterior, como Esther Hermitte, doctorada en Chicago y discípula de Sol Tax, enciende la esperanza en un cambio de rumbo. Los primeros egresados inician experiencias en áreas vinculadas a problemáticas actuales, colaborando con las nacientes escuelas de Trabajo Social o participando en investigaciones de antropólogos argentinos residentes en el exterior (tal el caso de Eduardo Menéndez con Ruben Reina en Paraná). Otros se insertan en instituciones nacionales que ofrecen algún espacio, si bien restringido, como el Instituto Nacional de Antropología o el Instituto Nacional de Tecnología Agropecuaria (INTA).

La instalación de órganos de gobierno democráticos, electos por los tres claustros (profesores, graduados y estudiantes), así como la paulatina cobertura de cargos docentes por concurso, abre esperanzas de cambio. Pero el gobierno democrático de Arturo Ilia, si bien limitado en su representatividad por la proscripción peronista, es derrocado por un golpe de Estado. 


\section{Bastones largos y primer exilio: 1966. Reacciones internas}

La "Revolución Argentina" es un movimiento militar corporativista con proyectos de permanencia. En lo universitario, demora su intervención en la universidad, pero irrumpe en ella con singular violencia, apaleando profesores. Una ola de renuncias es la respuesta, así como la partida hacia el exilio de muchos profesionales. Entre ellos, algunos antropólogos que van a Chile o Venezuela. Este es el año de la creación de la Licenciatura en Antropología de Rosario (Santa Fe), que nace muy condicionada.

Los antropólogos argentinos que permanecen buscan espacios de continuidad en instituciones privadas, como el Instituto Di Telia, donde trabaja Esther Hermitte, y otros múltiples centros en los cuales profesionales de diversas especialidades intentan captar clientela entre los desolados estudiantes de la universidad devastada. Entre otros, el Centro de Estudios del Habitat y el Centro de Medicina de Buenos Aires. Allí la interdisciplina se impone naturalmente en la convivencia con médicos, psicólogos o arquitectos.

En lo estrictamente antropológico funciona desde 1963 en Olavarría el Museo Etnográfico y luego el Instituto de Investigaciones Antropológicas, creado por Guillermo Madrazo, donde se ofrece espacio a los antropólogos sociales, aunque mayoritariamente se ocupa de arqueología. Su revista Etnía publica por primera vez trabajos de antropología social en este período.

En esa época se reafirma en la antropología social argentina un acendrado antimperialismo. Ello se refleja en debates y crítica ideológica a todo cuanto pueda significar condicionamiento. Se rechaza públicamente el Proyecto Marginalidad, análogo al Plan Camelot y no se aceptan financiamientos como los de la Fundación Ford. Es por ello que hay críticas hacia antropólogos que van a hacer su posgraduación en el Museo Nacional de Rio de Janeiro en un curso apoyado por dicha Fundación. Momento especial en la vida del país se opera, a la luz de acontecimientos sociales significativos -como los levantamientos populares denominados cordobazo y rosariazo- una asimilación del fenómeno peronista por las esferas intelectuales. El proyecto militar se resquebraja y a la dictadura Férrea de Onganía sucede el intento de conciliación del General Lanusse. En ese momento se consigue la creación, en la Universidad Provincial de Mar del Plata, de una interesante carrera de antropología, dirigida por Eduardo Menéndez, con un enfoque antropológico-social e instancias interdisciplinarias con historiadores y sociólogos. 
Hay cierta apertura en la Universidad de Buenos Aires -con la excepción de la carrera de antropología- donde aparecen las llamadas cátedras nacionales. Desde éstas se intenta integrar elementos de la vertiente marxista, tanto leninistas como chinoistas, con una interpretación original del peronismo, que rescata sus tendencias obreristas y revolucionarias. Aparece así un nacionalismo de izquierda paralelamente con el surgimiento de organizaciones guerrilleras que postulan la toma del poder por las armas. Un estado general de debate político conmueve a la sociedad, y se multiplican los ensayos interpretativos del peronismo.

\section{El interregno democrático: la ilusión revolucionaria (1973-74)}

El regimen debe ceder y otorgar elecciones. Por primera vez desde 1955 el peronismo no es proscripto. La alianza que encabeza gana estruendosamente las elecciones del 11 de marzo de 1973. Se inicia un período muy convulsionado de lucha entre sectores de izquierda y de derecha dentro del movimiento peronista. La izquierda domina la universidad porteña, que pasa a llamarse Universidad Nacional y Popular de Buenos Aires.

En antropología se intenta una reforma de plan de estudios, con la implantación de dos orientaciones, arqueología y antropología social. Esto último suena a sacrilegio para aquellos que la combatieron en nombre de un estereotipo. Esta es la única época en que los informantes invaden los claustros académicos: indios en conflicto, pobladores urbanos que reclaman viviendas, campesinos, vecinalistas y obreros acuden a la Facultad en busca de respuestas o apoyo para sus problemas. La reforma propone especializar a los antropólogos futuros en temas de vivienda, cuestiones indígenas, educación y salud.

Desde la época anterior actúan en el país profesionales formados en el exterior, en especial en el área de antropología rural, quienes dan gran impulso a la disciplina. Entre ellos Leopoldo Bartolomé, Luis Gatti, Eduardo Archetti y Hebe Vessuri. En Tucumán discuten, por ejemplo, sobre la modalidad concreta que debería tener un proceso de reforma agraria que parecía inminente. La reacción, sin embargo, se impone, y en 1974 se interviene la Universidad y se pone en marcha un proyecto retrógrado.

En antropología regresa la conducción histórico-cultural fenomenológica que se vería confirmada luego por la siguiente dictadura militar. Mientras tanto se crean dos nuevas carreras de antropología: una en Salta y otra en Misiones. La segunda se dedica exclusivamente a la antropología social. 
Logrará persistir conservando un buen nivel académico bajo la conducción de Leopoldo Bartolomé, y ofrecerá asilo a antropólogos expulsados de otras universidades durante la dictadura que se avecina.

\section{Proyecto genocida y universidad: la dictadura militar 1976-83}

Muerto Osvaldo Menghin, Marcelo Bórmida asume plenamente la conducción de la antropología, no solo en Buenos Aires. Reafirma su posición en el CONICET -que no había perdido en el período anterior- y desde allí controla la esfera de investigación. Bajo la dictadura militar el grupo conoce su mayor cuota de poder.

Un gobierno que sospecha de la gramática estructural y las matemáticas modernas, que propicia quemas públicas de libros, no puede menos que perseguir a las ciencias sociales en general y a la antropología social en particular. El nombre de esta última especialidad se borra, y regresan las tradicionales orientaciones en arqueología, etnología y folklore. No solo eso, sino que se cierran carreras como las de Rosario y Mar del Plata, y se intenta lo mismo en Buenos Aires, donde antropología debía ser una especialización de posgrado para historiadores. La propuesta es impulsada por quienes -paradójicamente- habían creado el curso capitalino. El denodado esfuerzo del Colegio de Graduados en Antropología -fundado en 1972- acompañado por toda la comunidad científica, consigue frenar la propuesta.

La ola de prisiones, muertes y desapariciones alcanza también a la antropología. En rigor, comienza antes del golpe militar con la reacción de la derecha peronista (encarnada en José López Rega). Esta vez el exilio es intenso, y no solo por razones académicas, sino también de preservación de la vida. La diáspora se expande por toda América y Europa, donde los profesionales argentinos alcanzan, en casi todos los casos, posiciones destacadas. En el continente las colonias más numerosas son las de Brasil y México. Con la temprana muerte de Marcelo Bórmida, en 1978, su discípulo Mario Calilano asume la conducción y refuerza el Instituto privado (CAEA) que, con el apoyo del CONICET, crearan previsoramente en 1973. Pocos espacios restan para los antropólogos sociales que permanecen en el país. La mayoría abandona el ejercicio activo de la profesión. Esther Hermine persiste merced a su prestigio internacional e instala en el IDES un área de antropología social a la que acuden jóvenes deseosos de suplir las fallas formativas del curso oficial. Blas Alberti también procura, desde un Instituto privado, contrarrestar a la antropología oficial. 


\section{Democratización y reinstalación de la antropología social}

Conocida es la historia de la reinstauración democrática en la Argentina, y en el continente. En la esfera universitaria esto significó el retorno al gobierno tripartito, electo por los claustros, y a la provisión de las cátedras por concurso. De ninguna forma, sin embargo, se afectó la estabilidad de docentes e investigadores del período anterior. Estos reivindicaron los concursos condicionados que se celebraron hacia fines del gobierno militar, y ganaron sus causas en la justicia.

El retorno democrático significó la vuelta de la estigmatizada antropología social. Esta vez, designando orientaciones dentro de carreras y perdiendo toda connotación contestataria. Con el tiempo pasó a significar cualquier tipo de antropología no arqueológica, englobando incluso la antigua etnología. Tendió a englobar áreas temáticas, como antropología médica, antropología de la educación, rural, urbana, de género, visual, etc. El Folklore persiste en una orientación muy diferente al tradicionalismo superviviente anterior. Muchos folkloristas, sin embargo, han preferido orientarse hacia la antropología general, o sea social.

En lo académico se reactiva la carrera de Salta, casi paralizada, y se crean otras dos en Jujuy y Olavarría. Por primera vez se formalizan cursos exclusivamente de arqueología, donde se dictan materias de antropología social, en Tucumán y Catamarca.

Folklórica pasó a ser la idea de que ser antropólogo social indicaba una autodefinición progresista o de izquierda. Anacrónica también la presunción derechista de que la antropología social encarnaba poco menos que el anti-Cristo, y que debía ser destruida. La discusión no pasa más por allí, aunque dejó resabios.

En general hay poca reflexión escrita, o balances, sobre esta última etapa de la antropología argentina (Cfr. Herrán, 1993). Los trabajos que intentan una visión de conjunto suelen concluir con la mención de la apertura democrática, incluyendo algún párrafo esperanzado hacia el futuro. Sin embargo hace más de diez años que la antropología argentina ha reasumido su puesto en el debate mundial de la disciplina, ha investigado temas y ha dicho cosas. La presencia de profesionales en foros internacionales es constante, y ya se podrían avizorar tendencias. Por nuestra parte nos animaríamos por ahora a apuntar algunas características del período.

A) Retorno y aportes. La diáspora ha vuelto. Retornan antropólogos con experiencias diversas hechas en la academia y el campo mexicanos, brasileños, 
ecuatorianos o europeos. Esto fertiliza a la antropología argentina y crea puentes internacionales, fruto de lo que podríamos llamar síndrome del exilio: el conflicto de lealtades en los ex-exiliados entre el país que fue anfitrión y la devastada antropología nacional. Bibliografía inédita aparece en cátedras y grupos de investigación. En algunos casos se concretan convenios que llevan a jóvenes argentinos a completar su formación en el exterior. No todos han vuelto. No obstante, aún aquellos que resolvieron permanecer en el extranjero hacen periódicas entradas y aportes a la antropología nacional. Estos profesores visitantes también tratan de componer de esta forma el conflicto que les genera su no retorno. Constituyen una magnífica vía de renovación para la ciencia local.

B) Vueltas atrás. El impulso a la investigación durante el primer gobierno democrático se tradujo en la renovación del órgano rector del fomento científico, el CONICET, cuyas comisiones asesoras abrieron los no muy abundantes recursos a las nuevas orientaciones. Del mismo modo desde la Secretaría de Cultura se creó la Dirección Nacional de Antropología y Folklore que conducía, entre otras cosas, al viejo Instituto Nacional de Antropología.

En ambas instancias hubo novedades. Tales las becas y el ingreso a la carrera de Investigador de nuevas promociones sin que, bueno es repetirlo, se viera afectada la trayectoria de quienes estaban en ella durante el período anterior. En la Dirección Nacional y el Instituto fueron memorables los Encuentros nacionales y regionales de antropólogos, donde se debatieron todo tipo de problemas profesionales.

Esto se revirtió a partir de 1989. Sorpresivamente, el nuevo gobierno reinstaló en el CONICET una Comisión Asesora integrada por representantes de quienes fueron conducción durante los períodos autoritarios. Se intenta excluir nuevamente a quienes practican la antropología social, acusándolos de sociologistas. Se reivindica como etnografía solo al estudio de los indígenas, y se dejan retroceder alarmantemente los recursos destinados a investigación antropológica.

Los Encuentros de antropólogos se cortan, se disuelve la Dirección Nacional de Antropología y Folklore, y en el Instituto Nacional de Antropología (ahora con el agregado de "y Pensamiento Latinoamericano") se reinstala la anterior conducción.

Esta reseña puede parecer, a ratos, excesivamente política. No se ha profundizado en muchas tendencias teóricas debatidas en antropología antes y ahora, por ejemplo. Y es que nuestra visión no puede apartarse de los 
condicionantes político-administrativos de la disciplina. Fueron demasiado importantes. Condicionaron nuestro desarrollo académico, nos mantuvieron en una posición marginal, afectaron profundamente nuestras vidas profesionales y privadas. Marcar la aparición de tendencias regresivas debería preocuparnos. Lo mismo la ofensiva privatista que aspira a eliminar la conducción estatal de la investigación científica.

Lo que mantiene la esperanza, sin embargo, es la persistencia de la estructura democrática. Ya no va a ser tan fácil suprimir carreras, restringir recursos sin dar razón o imponer sin más resoluciones arbitrarias. Así como los personeros de las dictaduras utilizaron para subsistir los resortes democráticos, no pueden obrar ahora como antes. Los más lúcidos de entre ellos ya recurren a la negociación. Algo de las buenas iniciativas persiste, a regañadientes de quienes deben soportarlas. La antropología argentina está conectada con el mundo, puede recurrir a foros internacionales. Eso nos hace retomar la lucha con nuevos bríos, encararla con otro espíritu. En democracia, toda rectificación es posible.

\section{Referencias}

ARENAS, P. La Antropología en la Argentina a fines del siglo XIX y principios del XX. Runa, Buenos Aires, v. 19, 1989-1990.

ARENAS, P. Antropología en la Argentina: el aporte de los científicos ele habla alemana. Buenos Aires: Institución Cultural Argentino-Germana: Museo Etnográfico “J.B. Ambrosetti”, 1991.

GARBULSKY, E. O. José Imbelloni. Postivismo, organicismo y racismo. Cuadernos de la Escuela de Antropología, Rosario: UNR, v. 3, n. 87, 1987.

GARBULSKY, E. O. La antropología de los años cuarenta y su concepción de la formación étnica argentina. Un caso de racismo "científico". In: REFLEXIONES SOBRE EL V CENTENARIO. Rosario: UNR Editora, 1992. p. 103-114.

GARBULSKY, E. O. La antropología social en la Argentina. Runa, Buenos Aires, v. 20, 1991-1992. 
GONZALEZ, A. R. A cuatro décadas del comienzo de una etapa. Apuntes marginales para la historia de la Angropología argentina. Runa, Buenos Aires, v. 20, p. 91-110, 1991-1992.

HERRÁN, C. Antropología Social en la Argentina: apuntes y perspectivas. Cuadernos de Antropología Social, Buenos Aires, v. 2, p. 108-115, 1990.

HERRÁN, C. Tendencias actuales de la investigación antropológica en la Argentina. Plural, Campinas, n. 2, p. 5-10, 1993.

IMBELLONI, J. Antropología, Investigadores e Investigaciones. Etapas de esta ciencia en nuestro país. In: $1^{\circ}$ CICLO ANUAL DE CONFERENCIAS: volumen 1: novena conferencia. Buenos Aires: Ministerio de Educación de la Nación, Subsecretaría de Cultura, 1954.

LAFON, C. R. Nociones de introducción a la antropología. Buenos Aires: Editorial Glauco, 1976.

MADRAZO, G. B. Determinantes y orientaciones en la antropología Argentina. Boletín del IIT, Buenos Aires: Facultad de Filosofía y Letras de la UBA, Instituto Interdisciplinario Tilcara, 1985.

RATIER, H. E. Antropología Social en Argentina y Brasil: teorías y prácticas. 1983. Ponencia. I Congreso Argentino de Antropología Social, Posadas, setiembre 1983.

RATIER, H. E. Construcción de la antropología social en la Argentina. 1986. Seminario-Taller Antropología, Disciplina Científica y Práctica Profesional, La Plata, nov. 1986.

RATIER, H. E. Antropología, democracia y dictaduras: desarrollo de una categoría profesional en la Argentina. Plural, Campinas, n. 2, p. 6-17, 1993.

RINGUELET, R. A propósito de la Antropología de los 90. Publicar, Buenos Aires, año 1, n. 2, p. 81-88, oct. 1992.

STAGNARO, A. A. La antropología en la comunidad científica: entre el origen del hombre y la caza de cráneos-trofeo. Alteridades, México: Universidad Autónoma Metropolitana, año 3, n. 6, p. 53-65, 1993. 